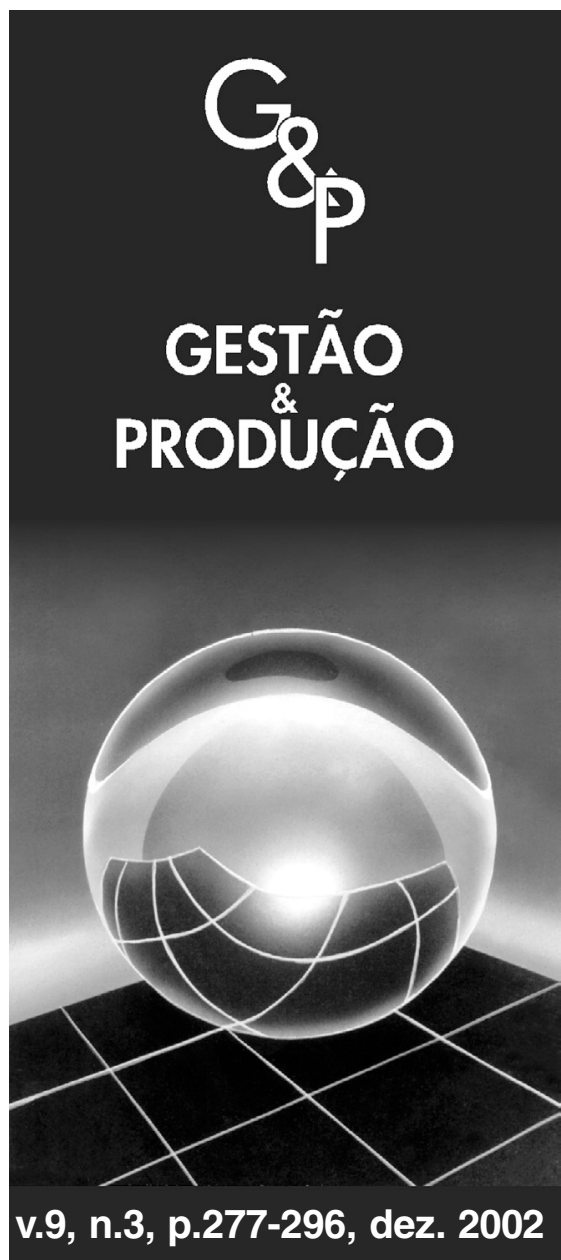

\title{
SISTEMAS INTEGRADOS DE GESTÃO ERP EM PEQUENAS EMPRESAS: UM CONFRONTO ENTRE O REFERENCIAL TEÓRICO E A PRÁTICA EMPRESARIAL
}

\author{
Juliana Veiga Mendes \\ Departamento de Ciência da Computação, \\ Centro Universitário da FEI - UNIFEI, \\ Rua Tamandaré, 688 - Campus SP, \\ CEP 01525-000, São Paulo, SP, \\ e-mail: juveiga@esan-sp.edu.br
}

Edmundo Escrivão Filho

Departamento de Engenharia de Produção, Escola de Engenharia de São Carlos - USP, Av. Trabalhador Sancarlense, 400,

CEP 13566-590, São Carlos, SP, e-mail: edesfi@prod.eesc.sc.usp.br

\section{Resumo}

Nos últimos anos, os sistemas integrados de gestão, ou ERP (Enterprise Resource Planning), passaram a ser largamente utilizados pelas empresas. Eles são apresentados como "solução" para a maioria dos problemas empresariais. São sistemas genéricos capazes de integrar todas as informações que fluem pela empresa por intermédio de uma base de dados única. A literatura sobre o assunto apresenta uma série de resultados positivos e benefícios a serem obtidos com a adoção desses sistemas. Porém, as dificuldades a serem enfrentadas e a profundidade das mudanças a serem realizadas para a obtenção dos benefícios não são tão claras para as empresas, principalmente para as de pequeno porte, que não possuem tantos recursos para investimento em tecnologia. Este artigo tem por objetivo relatar o resultado de uma pesquisa sobre a adoção de sistemas integrados de gestão, ou ERP, por pequenas empresas, confrontando o referencial teórico e a prática empresarial.

Palavras-chave: sistemas integrados de gestão, pequenas e médias empresas, mudança organizacional, integração, sistemas de informação. 
$\mathrm{N}$ o início da década de 90 , os sistemas integrados de gestão ou ERPs (Enterprise Resource Planning) passaram a ser largamente utilizados pelas empresas. Nessa época, eram extremamente caros, viáveis somente para empresas de grande porte. No transcorrer dessa década, as grandes corporações fizeram suas escolhas sobre os sistemas a serem adquiridos e implantados, saturando assim o mercado das grandes empresas e reduzindo as possibilidades de negócio para os fornecedores de ERPs nesse segmento empresarial (Corrêa, 1998).

Restou então o mercado intermediário formado pelas pequenas e médias empresas (PMEs); nesse novo contexto, diversas empresas fornecedoras de ERPs, até então direcionadas para o segmento das grandes organizações, lançaram estratégias de atuação diferenciadas para competir nesse mercado. As PMEs ficaram sob intensa campanha mercadológica das empresas fornecedoras dos ERPs e, muitas vezes, sem referencial para avaliar a aquisição.

Dentro desse contexto, este artigo tem por objetivo relatar o resultado de uma pesquisa sobre a adoção de sistemas ERPs por pequenas empresas, confrontando o referencial teórico e a prática empresarial e revelando, de forma imparcial, o comportamento dessas empresas no processo de adoção de ERPs.

A análise teórica se concentrou em livros, publicações acadêmicas e revistas especializadas e de negócios que discorriam sobre os sistemas ERPs. É importante ressaltar que a maioria dessas publicações não se baseou no ambiente das PMEs, mas das grandes empresas. São poucas as publicações existentes que relacionam sistemas ERPs e PMEs. Essas publicações são realizadas pela mídia de negócios e semanários e, em geral, enfatizam que o mercado de sistemas ERPs se voltou para esse segmento, mas não discutem o assunto e as possíveis implicações dessa situação.

Os dados empíricos foram levantados a partir de um estudo em dez pequenas empresas situadas na Grande São Paulo e classificadas nos setores industrial e de serviços.

\section{Referencial teórico}

A análise das publicações permitiu estruturar o tema pesquisado em quatro aspectos básicos. São eles: 1. caracterização dos sistemas ERPs; 2. aspectos relevantes ao sucesso na implantação; 3. resultados esperados com a adoção dos ERPs; e 4. barreiras e dificuldades com a implantação de ERPs.

\subsection{Caracterização dos sistemas ERPs}

Para Lima et al. (2000), a adoção de um ERP afeta a empresa em todas as suas dimensões, culturais, organizacionais ou tecnológicas. Esses sistemas controlam toda a empresa, da produção às finanças, registrando e processando cada fato novo na engrenagem corporativa e distribuindo a informação de maneira clara e segura, em tempo real. Ao adotar um ERP, o objetivo básico não é colocar o software em produção, mas melhorar os processos de negócios usando tecnologia da informação. Mais do que uma mudança de tecnologia, a adoção desses sistemas implica um processo de mudança organizacional.

Souza \& Zwicker (2000) definem como sistemas de informação integrados, adquiridos na forma de pacotes comerciais, para suportar a maioria das operações de uma empresa. Procuram atender a requisitos genéricos do maior número possível de empresas, incorporando modelos de processos de negócio obtidos pela experiência acumulada de fornecedores, consultorias e pesquisa em processos de benchmarking. A integração é possível pelo compartilhamento de informações comuns entre os diversos módulos, armazenadas em um único banco de dados centralizado.

De acordo com Buckhout et al. (1999), um ERP é um software de planejamento dos recursos empresariais que integra as diferentes funções da empresa para criar operações mais eficientes. Integra os dados-chave e a comunicação entre as áreas da empresa, fornecendo informações detalhadas sobre as operações da mesma. 
Para Centola \& Zabeu (1999), o ERP fornece informações geradas a partir do processo operacional, para otimizar o dia-a-dia da empresa, permitir um planejamento estratégico mais seguro e garantir a flexibilidade para evoluir.

Segundo Corrêa et al. (1997), um ERP é constituído por módulos que atendem às necessidades de informação de apoio à tomada de decisão de todos os setores da empresa, todos integrados entre si, a partir de uma base de dados única e não redundante. Podem ser entendidos como evolução do MRP II na medida em que controlam tanto os recursos diretamente utilizados na manufatura quanto os demais recursos da empresa.

Segundo Dempsey (1999), o ERP dispõe de um conjunto de programas capazes de interligar os aspectos da manufatura e incorporar os procedimentos contábeis ou dados gerados por outros aplicativos. Embora a definição seja atraente, muitas empresas desconhecem os problemas e cuidados relacionados a esses sistemas.

Hehn (1999) apresenta o ERP como uma evolução expandida do MRP II. Eles representam uma coleção integrada de sistemas que atendem a todas as necessidades de um negócio: contabilidade, finanças, controle de produção, compras e outros. Todos os sistemas estão integrados e partilham os mesmos dados. Trazem embutidos em si processos de trabalho padronizados, procurando representar as melhores práticas mundiais de cada função. A adoção desses sistemas exige disciplina e os usuários devem mantê-los atualizados.

Segundo Miltello (1999), o ERP controla a empresa, manuseando e processando suas informações. Todos os processos são documentados e contabilizados, gerando regras de negócio bem definidas e permitindo maior controle sobre alguns pontos vulneráveis do negócio, como a administração de custos, controle fiscal e estoques. A adoção desses sistemas põe fím aos vários sistemas que funcionavam de forma isolada na empresa, com informações redundantes e não confiáveis.

Para Cunha (1998), o ERP é um modelo de gestão baseado em sistemas corporativos de informação que visam integrar os processos de negócio da empresa e apoiar decisões estratégicas. O modelo desse sistema tem uma abrangência de atuação que envolve as várias entidades de negócios, integrando a cadeia de suprimentos de fornecedores a clientes e buscando endereçar as questões de competitividade das organizações empresariais. Representa uma evolução do MRP II.

Para Davenport (1998), o ERP é um software que promete a integração das informações que fluem pela empresa. Esse sistema impõe sua própria lógica à estratégia, à cultura e à organização da empresa. É uma solução genérica que procura atender a todo tipo de empresa e seu projeto reflete uma série de hipóteses sobre como operam as organizações. É desenvolvido para refletir as melhores práticas de negócio, porém são os clientes que devem definir a melhor prática para sua empresa.

Em uma publicação da Deloitte Consulting (1998), o ERP é definido como um software de negócio que permite à empresa automatizar e integrar a maioria de seus processos; compartilhar práticas de negócio e dados comuns pela empresa; e disponibilizar a informação em tempo real. É visto como a solução para acabar com os vários programas que funcionam no mesmo ambiente empresarial, sem integração, produzindo informações de pouca qualidade para o negócio. Sistemas dessa natureza são adquiridos com o intuito de tornar os processos empresariais mais ágeis e extrair informações mais acuradas da empresa.

Em reportagem da revista Informática Exame (1997), o ERP é citado pela capacidade de colocar nos "eixos" toda engrenagem empresarial. A adoção obriga a corporação a repensar sua estrutura e seus processos. Esse sistema põe fim às aplicações redundantes e incompatíveis existentes nas empresas e muitos estão preparados para o comércio eletrônico e outras vantagens surgidas com a Internet.

Segundo Stamford (2000), o ERP possibilita um fluxo de informações único, contínuo e consistente por toda a empresa sob uma única base de dados. É um instrumento para a melhoria 
de processos de negócio, orientado por esses processos e não pelas funções e departamentos da empresa, com informações on-line em tempo real. Permite visualizar por completo as transações efetuadas pela empresa, desenhando um amplo cenário de seus processos de negócios.

Para Wood Jr. (1999), esses sistemas são, teoricamente, capazes de integrar a gestão da empresa, agilizando a tomada de decisão. Podem ser aplicados, com adaptações, a qualquer empresa, permitindo o monitoramento em tempo real. As expectativas sobre seu impacto são enormes e os investimentos, gigantescos. Eles surgiram da confluência de fatores como: integração de empresas transnacionais exigindo tratamento único e em tempo real da informação; tendência de substituição de estruturas funcionais por estruturas ancoradas em processos; e integração dos vários sistemas de informação em um único sistema.

Pela Tabela 1 verifica-se, sinteticamente, a perspectiva dos autores citados anteriormente quando caracterizam um ERP. Ao analisar essas caracterizações podem ser percebidas diferenças na abrangência e na profundidade utilizadas por cada autor. $\mathrm{O}$ entendimento de ERP compreende desde um conjunto de programas de computador até um sistema de informação gerencial que visa apoiar as decisões estratégicas da empresa. As células em branco consistem em características não destacadas pelos autores. Nas demais tabelas apresentadas no artigo, as células em branco possuem o mesmo significado.

Em relação à base de dados única, esta característica permite que a mesma informação seja compartilhada por toda a empresa, reduzindo os problemas de inconsistência e duplicidade e conferindo confiabilidade às informações do sistema. O ERP armazena as informações da empresa em um banco de dados corporativo, solucionando o problema de ter a mesma informação com valores distintos em diferentes relatórios.

O ERP é constituído por vários "módulos" que suportam todas as áreas de uma empresa. Por se tratar de sistema genérico, independe do fato de a empresa que vai adotá-lo ser de manufatura ou prestadora de serviços. A abrangência do sistema é limitada pela empresa, podendo estar atrelada a vários motivos, como: custo de implantação dos módulos, possibilidade de integração de sistemas menores ao ERP, entre outros.

O suporte à necessidade de informação é viabilizado pela disponibilidade e integridade das informações armazenadas no ERP, na base única e centralizada. Como o sistema permeia toda a empresa, as informações que por ela circulam podem ser acessadas em tempo real, por qualquer área.

A orientação a processos é destacada por muitos autores na caracterização de ERP. Segundo Souza \& Zwicker (2000), os processos de negócio podem ser definidos como um conjunto de tarefas e procedimentos interdependentes realizados para alcançar determinado resultado empresarial, sendo uma de suas características a transposição de fronteiras organizacionais.

A integração da empresa, facilitada pelo uso de ERP, é decorrente de alguns fatores, como: possibilidade de a empresa operar com um único sistema de informação que atenda a todas as suas áreas; armazenamento dos dados em um banco de dados único e centralizado; e orientação a processos. Os processos, implementados no sistema, não se restringem a uma área ou departamento, quebrando barreiras impostas pelas estruturas departamentais.

No que se refere ao controle da empresa, o ERP, por sua concepção, impõe sistematização no lançamento das informações, permitindo o controle em tempo real. Assim, o sistema sempre refletirá a situação atual da empresa.

Buckout et al. (1999) apresentam o ERP como um software de planejamento, mas sabe-se que ele não se limita a isso, e os próprios autores expandem essa definição ao mencionarem que ele integra as diferentes áreas da empresa, criando operações mais eficientes, permitindo a comunicação entre as áreas, fornecendo informações detalhadas e possibilitando, assim, o controle das funções por ele suportadas. 
Tabela 1 - Características dos sistemas ERPs.

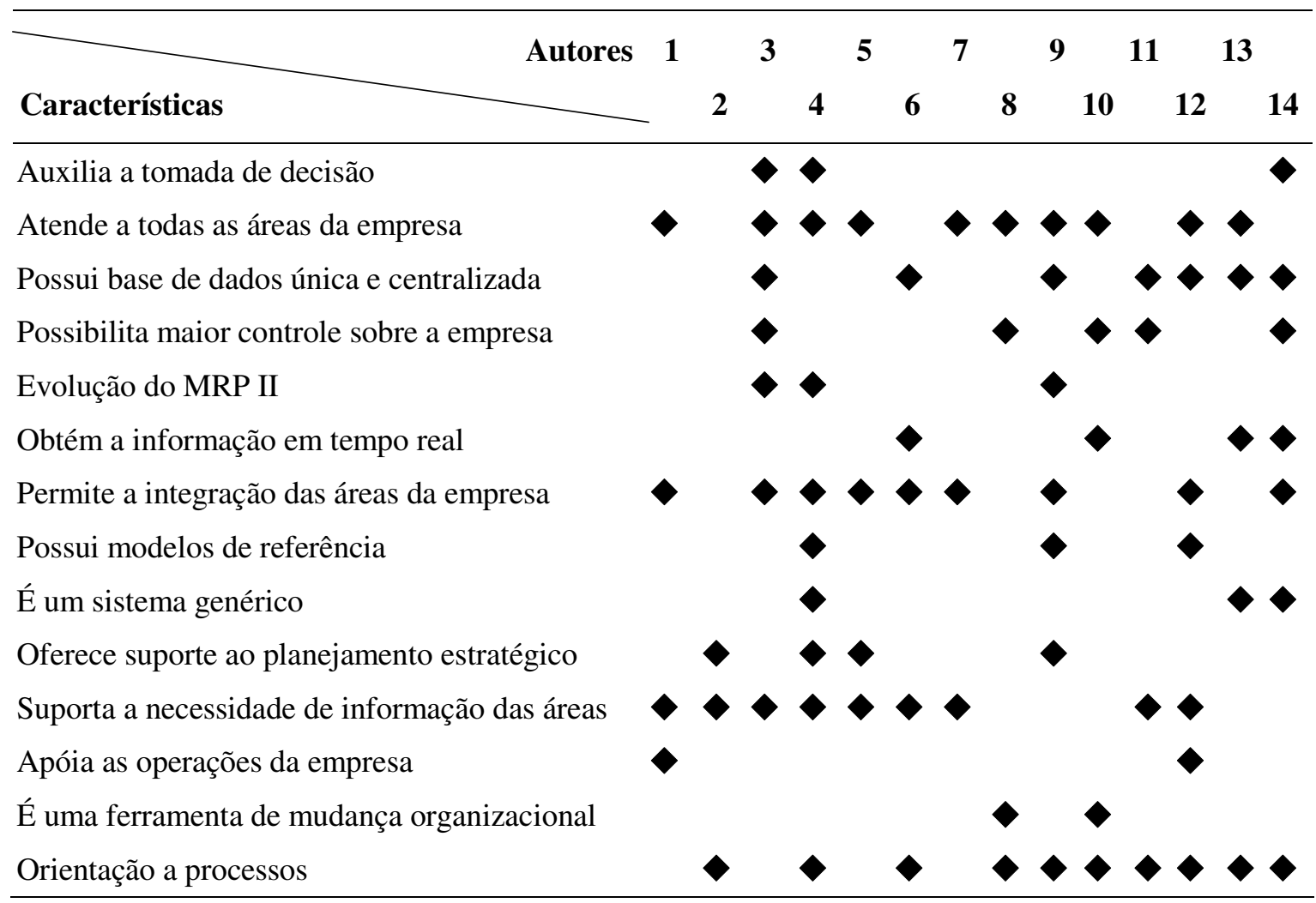

Legenda:

1 - Buckhout et al. (1999)

6 - Deloitte Consulting (1998)

11 - Miltello (1999)

2 - Centola \& Zabeu (1999)

7 - Dempsey (1999)

12 - Souza \& Zwicker (2000)

3 - Corrêa et al. (1997)

8 - Informática Exame (1997)

13 - Stamford (2000)

4 - Cunha (1998)

9 - Hehn (1999)

14 -Wood Jr. (1999)

5 - Davenport (1998)

10 - Lima et al. (2000)

Corrêa et al. (1997) caracterizam o ERP como uma evolução do MRP II. Na verdade, os autores querem dizer que a lógica, isto é, o embrião do ERP, é o MRP desenvolvido para os ambientes de manufatura. A partir disso, foram sendo criados alguns sistemas, ou partes deles (módulos), adequados a outros ambientes.

\subsection{Aspectos relevantes ao sucesso na implantação do ERP}

Neste trabalho, o termo "implantação" compreende o processo de adoção do ERP, envolvendo seleção, aquisição, implantação e testes, que, segundo Mendes \& Escrivão Filho (2000), deve ser planejado, ter passado por uma etapa de análise das funcionalidades da empresa e do sistema e estar de acordo com a orientação estratégica da empresa.

Para Lima et al. (2000), o sucesso na implantação depende do alinhamento entre software, cultura e objetivos de negócio da empresa. É necessário ter: articulação entre os objetivos do projeto e expectativas de mudança da organização; boa gerência; comprometimento da alta administração e dos proprietários dos processos; e os usuários devem compreender a mudança. $\mathrm{Na}$ seleção deve-se avaliar o sistema mais adequado 
à empresa. A implantação é um processo caro, demorado e obriga a corporação a repensar sua estrutura e processos. A equipe de implantação deve conhecer o sistema e os processos de negócio da empresa.

Souza \& Zwicker (2000) ressaltam esta etapa como a mais crítica, destacando a importância de checar: funcionalidades e adequação do sistema às particularidades da empresa e o fornecedor da solução. Após a seleção, definese um líder e a equipe de implantação. Fatores importantes na implantação são: experiência dos usuários com sistemas e conhecimento prévio sobre as discrepâncias entre o sistema e a empresa; comprometimento da alta direção; envolvimento das áreas usuárias e de tecnologia; e treinamento para os usuários finais. É um processo de mudança organizacional envolvendo mudança nas responsabilidades e tarefas das pessoas e nas relações entre os departamentos.

Segundo Stamford (2000), o sucesso de um sistema desse porte é determinado pela previsão do impacto para a empresa. Na prática, muitas organizações não levam em consideração todas as mudanças necessárias, as quais envolvem estrutura, operação, estratégia e cultura da empresa. Na implantação é preciso determinar os objetivos a serem alcançados e como as funcionalidades do sistema podem ajudar nisso. Essa etapa deve contemplar a análise dos processos atuais, a possibilidade de modificá-los e o envolvimento do usuário.

Para Buckhout et al. (1999), a implantação de um ERP tem sido problemática por duas razões: a empresa não faz antes as escolhas estratégicas para configurar os sistemas e os processos e a implantação escapa do controle da empresa. Muitas empresas encaram como um projeto de tecnologia e não como um projeto empresarial. Além desses fatores, a alta direção deve estar comprometida e envolvida na implantação, indicando prioridades estratégicas e vinculando controles e incentivos para os envolvidos no sucesso do projeto.

Centola \& Zabeu (1999) destacam que a seleção pode ser demorada e complexa em razão do amplo espectro de funcionalidades do sistema a ser checado. Para a implantação, a empresa deve passar por treinamento conceitual e operacional, exploração do sistema, parametrização, redesenho dos processos e assimilação da nova cultura. É fundamental o envolvimento dos usuários nessa etapa.

Lopes et al. (1999) afirmam que o princípio do sistema é simples, porém sua implantação é difícil. Por se tratar de um produto flexível, o cliente faz a adequação do sistema para suas necessidades e, assim, a implantação pode levar vários anos. Em geral, a implantação é conduzida por empresas de consultoria, elevando os custos do projeto.

Para Taurion (1999), implantar um ERP requer cuidados como: escolher o mais adequado às peculiaridades da organização e selecionar os parceiros envolvidos na implantação, como uma consultoria experiente no assunto. A implantação desse sistema refere-se a mudanças nos processos, suportados por um ERP e não por um pacote de informática. É um trabalho de reengenharia de alto impacto em toda a organização. $\mathrm{O}$ sucesso está atrelado ao gerenciamento do projeto, ao comprometimento da empresa e da alta administração e à formação de equipe com conhecimentos sobre o sistema e processos de negócio da empresa.

Para Wood Jr. (1999), a implantação é a etapa mais complexa. Trata-se de um amplo processo de mudança organizacional que provoca impactos no modelo de gestão, na arquitetura organizacional, no estilo gerencial, nos processos de negócios e, principalmente, nas pessoas. Deve envolver equipes multidisciplinares compostas por especialistas em tecnologia da informação, analistas de negócios e consultores com capacitação em redesenho de processos.

Para Corrêa (1998), o sucesso na adoção de um ERP se inicia na seleção. Deve-se realizar uma análise de adequação de funcionalidades para checar se as particularidades da empresa são atendidas. A implantação precisa ser gerenciada por pessoas que entendam de mudança organizacional e negócio, devendo ser conduzida por funcionários da empresa. É importante o com- 
prometimento da alta direção, que deve ter uma visão clara e compartilhada da situação futura. A implantação deve contemplar os aspectos de um projeto de mudança organizacional. Após a implantação é preciso esforço contínuo por meio de reciclagem no treinamento e comprometimento dos envolvidos.

A adoção desses sistemas requer a análise dos processos executados pela empresa. O objetivo é avaliar se os processos devem ser modificados, modernizados ou mantidos. A adequação das funcionalidades deve ser realizada na fase de seleção do sistema. O objetivo é checar se as funcionalidades são aderentes às particularidades da empresa. A Tabela 2 destaca os pontos importantes citados pelos autores na implantação de ERP.

O ideal é que, primeiramente, a empresa faça a análise de seus processos e, na seqüência, verifique a adequação das funcionalidades dos sistemas existentes. Essas análises devem ser conduzidas antes da aquisição do sistema, pois o resultado terá reflexo em todo o processo de implantação, tendo conseqüências no tempo de duração da implantação, na contratação de consultoria externa, nas customizações a serem realizadas, na profundidade da mudança, no treinamento dos usuários e, principalmente, no custo final do projeto.

O sucesso da implantação também está relacionado aos profissionais envolvidos, que além da competência técnica devem reunir bons conhecimentos do negócio. O gerente de implantação deve acompanhar os prazos, auxiliar na definição do escopo das modificações e não perder o foco do projeto. Os funcionários envolvidos devem ter bom conhecimento da empresa e das modificações que estão sendo introduzidas.

Tabela 2 - Aspectos relevantes ao sucesso na implantação do ERP.

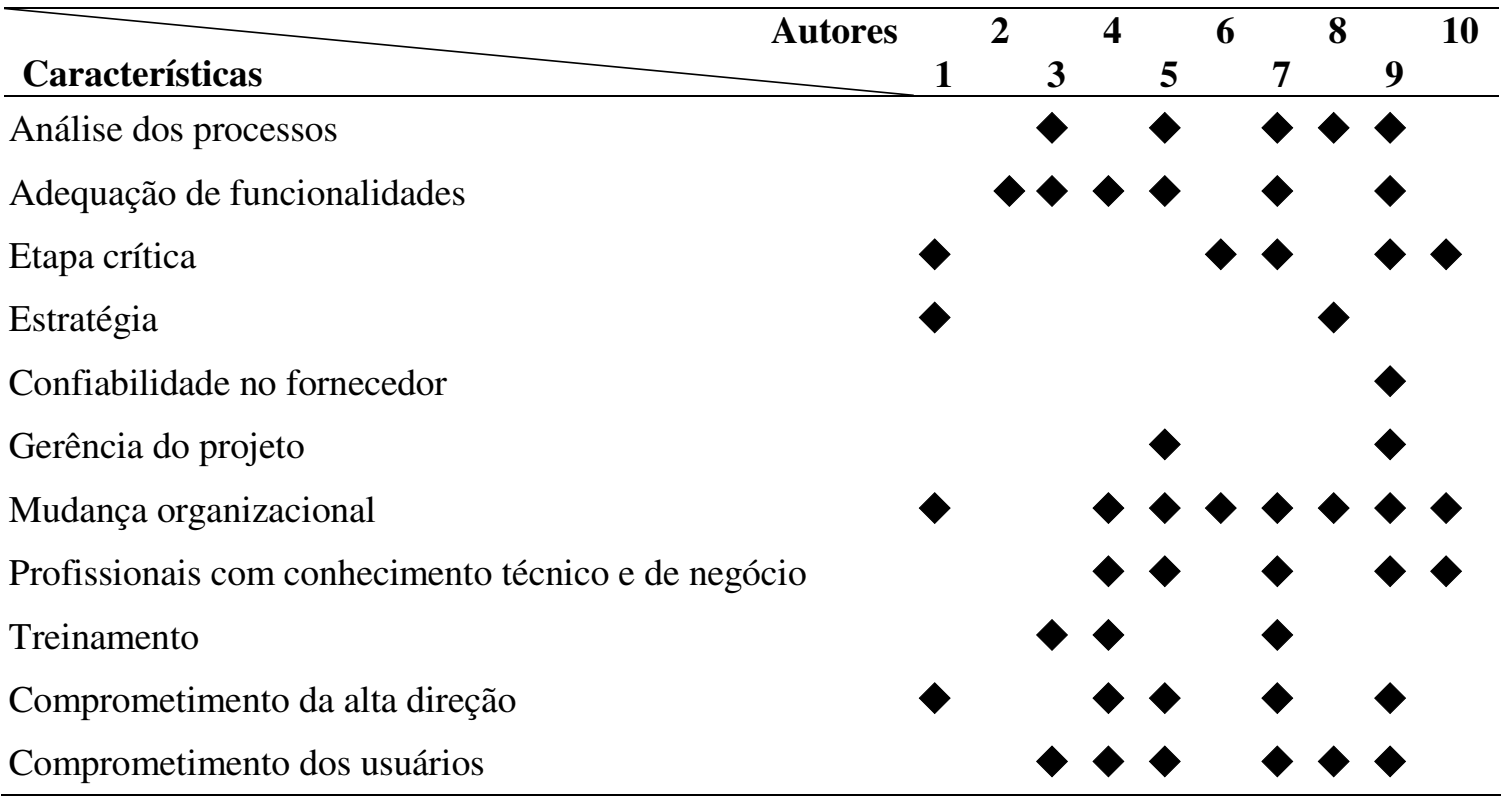

Legenda:

1 - Buckhout et al. (1999)

2 - Mendes \& Escrivão Filho (2000)

3 - Centola \& Zabeu (1999)

4 - Corrêa (1998)

5 - Lima et al. (2000)

$$
\begin{aligned}
& \mathbf{6} \text { - Lopes et al. (1999) } \\
& \mathbf{7} \text { - Souza \& Zwicker (2000) } \\
& \mathbf{8} \text { - Stamford (2000) } \\
& \mathbf{9} \text { - Taurion (1999) } \\
& \mathbf{1 0} \text { - Wood Jr. (1999) }
\end{aligned}
$$


A implantação de um ERP é tida por vários autores como uma etapa crítica e demorada, pois é um sistema abrangente, complexo e que deve refletir a realidade da empresa. Pela complexidade e modificações no funcionamento e na estrutura da empresa decorrentes do ERP, ele não deve ser encarado como um projeto de implantação de sistema de informação, mas como um projeto de mudança organizacional.

Por mudança organizacional compreende-se o processo de transformação do comportamento de um indivíduo ou de uma organização, podendo ser sistemática e planejada ou, ainda, implementada de forma aleatória. Gerenciar uma mudança em um ambiente organizacional implica mudar os hábitos, os modelos de comportamento e, às vezes, as atitudes das pessoas em relação ao modo de execução das funções, observam Daft (1999) e Montana \& Charnov (1999). Para Kruglianskas (1996), quando uma empresa introduz um novo método em atividades de manufatura, de serviços ou gerencial, está implantando uma mudança.

\subsection{Resultados esperados com a adoção do ERP}

Segundo Lima et al. (2000), a documentação e contabilização dos processos por intermédio do ERP geram regras de negócios bem definidas e permitem controle mais rígido sobre pontos vulneráveis do negócio. Para as empresas de médio porte, a adoção de ERP constitui excelente oportunidade para modernização tecnológica.

Para Souza \& Zwicker (2000), os resultados são percebidos após certo tempo de uso do sistema. As vantagens são: possibilidade de integrar os departamentos, permitir atualização da base tecnológica e reduzir custos de informática decorrentes da terceirização do desenvolvimento do sistema. O ERP tem sido utilizado como infraestrutura tecnológica para suporte às operações. Para obter os benefícios é preciso encará-lo como um projeto em evolução contínua e tomar as medidas gerenciais necessárias.
De acordo com Stamford (2000), o ERP contribui para aumentar a eficiência da empresa, otimizando a capacidade para fazer negócios em qualquer lugar do mundo. Como vantagens podem ser citados: aumento de valor percebido pelos investidores e pelo mercado; agilidade nas oportunidades de negócios; visibilidade; base única; informação em tempo real; atendimento a requerimentos globais, regionais e locais em um único sistema; e suporte à estratégia de $e$ business. O ERP é considerado a porta de entrada para a integração entre as empresas da cadeia de fornecedores e está se tornando uma plataforma para aplicações de data mining, gerenciamento da cadeia e sistemas de informação para executivos.

De acordo com Lopes et al. (1999), a vantagem do ERP é a integração de módulos informatizados que antes rodavam separadamente. Assim, a empresa deixa de operar como se existissem várias ilhas informatizadas e independentes. Além da integração, ele melhora a utilização dos recursos internos e traz economia para a empresa.

Para Miltello (1999), com o ERP, os processos são documentados e contabilizados, gerando regras de negócio bem definidas e permitindo que os pontos críticos do negócio possam ser controlados com mais rigor. Esse sistema põe fim à colcha de retalhos que caracteriza muitos sistemas corporativos, com programas redundantes, sem integração, tornando a consolidação dos dados demorada e ineficiente.

Para Taurion (1999), a adoção do ERP, principalmente para empresas de médio porte, é uma oportunidade de subir na escala tecnológica. A implantação sem a revisão dos processos resulta em ganhos de pouco alcance. As atividades dos funcionários se tornam mais abrangentes e complexas quando a empresa se reestrutura por processos. Por isso o treinamento não pode ser negligenciado.

Uma pesquisa realizada por Wood Jr. (1999) revela que, de modo geral, a implantação trouxe melhorias para a empresa, porém não se pode falar em unanimidade. Dentre as melhorias 
observadas, $60 \%$ das empresas analisadas afirmaram ter havido integração efetiva das funções e processos, $45 \%$ apontaram melhoria na utilização de recursos do sistema ou da tecnologia e $40 \%$ disseram ter melhorado o desenho e controle dos processos.

Cunha (1998) destaca que a opção por um ERP representa a criação de uma infra-estrutura de aplicativos fundamentada na tecnologia do sistema escolhido. As decisões futuras, relacionadas à modelagem dos processos de negócio e à implantação de novas soluções, deverão considerar a tecnologia estabelecida pelo sistema.

Davenport (1998) revela que o ERP permite o acesso à informação em tempo real e contribui para a redução de estruturas gerenciais. Por outro lado, centraliza o controle sobre a informação, padroniza processos e procura unificar a cultura e o comando sobre a empresa. Muitas empresas têm aproveitado esses sistemas para introduzir mais disciplina. O ERP auxilia a padronizar práticas administrativas para empresas distantes geograficamente.

Segundo pesquisa da Deloitte Consulting (1998), os benefícios de um ERP só podem ser obtidos na etapa de utilização se após a implantação o foco for mantido concentrando os esforços na obtenção dos resultados. A pesquisa revelou que as empresas sentiram os benefícios do sistema após algum tempo de uso, à medida que perceberam suas potencialidades de uso.

Segundo a revista Informática Exame (1997), com o ERP, os sistemas de informação deixaram de registrar o fluxo de informações e passaram a ajudar na gestão. Algumas empresas mediram os benefícios pela queda nos custos em informática.

Para Hehn (1999), organizações orientadas para processos, com forte rede de relacionamentos, integradas por um sistema, conseguem ser significativamente mais eficientes e eficazes que organizações departamentais tradicionais.

A empresa, ao adotar um ERP, cria uma base tecnológica fundada na tecnologia desse sistema. Assim, suas próximas aquisições tecnológicas deverão considerar o sistema implantado. A Tabela 3 destaca os resultados ressaltados pelos autores na adoção de um ERP.
A documentação dos processos empresariais e todos os procedimentos e formas de negócio suportados e documentados pelo ERP são resultados a serem destacados. A empresa ganha em controle e padronização de procedimentos e pode perder em flexibilidade. Após a implementação dos processos a empresa pode não ter recursos suficientes para arcar com os custos das modificações. Como consequiência, poderá desistir da mudança, deixando de inovar, ou o sistema deixará de refletir a prática empresarial.

A integração das diversas áreas da empresa também é facilitada pelo ERP. Os processos implementados no sistema transpõem os limites departamentais. $\mathrm{O}$ usuário, bem treinado conceitual e operacionalmente, pode visualizar a continuidade de sua tarefa, que antes se restringia ao departamento.

A implantação de um ERP contribui para que a empresa tenha maior controle sobre suas informações. Na base de dados única e centralizada, os dados são digitados uma só vez e todas as áreas podem consultá-los. Isso confere confiabilidade e integridade ao sistema, desde que o dado esteja atualizado e reflita a realidade da empresa.

Um resultado mencionado somente por Stamford (2000), que não consta na tabela, referese ao e-business. Como se refere a um novo caminho para a realização de negócios, vale a pena tecer um breve comentário. O ERP oferece suporte à estratégia de negócio eletrônico. Como as informações são armazenadas em uma única base de dados, sendo disponibilizadas em tempo real, torna-se mais fácil o acesso, para clientes e fornecedores, a informações necessárias para a realização de um negócio pela Internet.

\subsection{Barreiras e dificuldades com a implantação do ERP}

Para Lima et al. (2000), muitas empresas calculam de forma errada os custos relativos à implantação de um ERP. Os custos devem incluir: licenças do software; hardware; serviços de consultoria e treinamento; e ajustes após a implantação. 
Tabela 3 - Resultados obtidos na adoção do ERP.

\begin{tabular}{|c|c|c|c|c|c|c|c|c|c|c|c|}
\hline & Autores & & 2 & & 4 & & 6 & & 8 & & \\
\hline Características & & 1 & & 3 & & 5 & & 7 & & 9 & 11 \\
\hline Agilidade nos negócios & & & & & & & & & & $\diamond$ & \\
\hline Base de dados única & & & & & & & & $\diamond$ & & 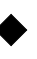 & \\
\hline Criação de uma base tecnológica & & $\diamond$ & & & & & & & & & \\
\hline Controle e gestão & & & & $\diamond$ & & $\diamond$ & & $\diamond$ & & $\checkmark$ & $\bullet$ \\
\hline Eficiência & & & & & $\diamond$ & & & & & & \\
\hline Obtenção da informação em tempo real & & & $\diamond$ & & & & & & & $\checkmark$ & \\
\hline Permite a integração das áreas da empresa & & & & & $\diamond$ & $\diamond$ & $\diamond$ & & & $\gamma$ & 4 \\
\hline Documentação de processos & & & $\diamond$ & & $\diamond$ & $\diamond$ & & $\diamond$ & & & 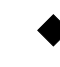 \\
\hline Regras de negócio definidas & & & $\diamond$ & & & $\diamond$ & & $\diamond$ & & & \\
\hline Redução de custos na área de informática & & & & $\diamond$ & & & & & & & \\
\hline Evolução tecnológica & & $\diamond$ & & & & $\diamond$ & & & & $\diamond$ & 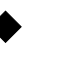 \\
\hline Empresa orientada a processo & & & & & $\diamond$ & & & & & & 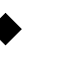 \\
\hline
\end{tabular}

Legenda:

1 - Cunha (1998)

2 - Davenport (1998)

3 - Informática Exame (1997)

4 - Hehn (1999)
5 - Lima et al. (2000)

6 - Lopes (1999)

7 - Miltello (1999)

8 - Souza \& Zwicker (2000)

$$
\begin{aligned}
& \text { 9-Stamford (2000) } \\
& \mathbf{1 0} \text { - Taurion (1999) } \\
& \mathbf{1 1 ~ - ~ W o o d ~ J r . ~ ( 1 9 9 9 ) ~}
\end{aligned}
$$

Segundo Souza \& Zwicker (2000), as principais dificuldades se referem à atualização constante do sistema e gerenciamento das versões. Mesmo após a implantação, o sistema mantém-se em evolução contínua, a fim de refletir os processos da empresa. Os fornecedores incorporam novos recursos e novas formas de executar processos e corrigem problemas. Muitas alterações podem ser consideradas novas implementações. A adoção de um ERP é um processo de mudança organizacional envolvendo alterações nas tarefas e responsabilidades de indivíduos, departamentos e relações entre os departamentos.

Para Stamford (2000), os problemas se referem à escala de reengenharia de processos, às tarefas de customização durante a implantação, à inexperiência da equipe de suporte, à implantação longa, ao alto custo relacionado à consultoria e treinamento, à complexidade na customização e aos benefícios que nem sempre se concretizam. A implantação e os serviços associados custam até sete vezes mais do que a compra do software. Outro problema refere-se à premissa de que os modelos de referência do sistema incorporam as melhores práticas de negócios. Pode haver desencontros entre, por exemplo, tipo de indústria e melhores práticas desse segmento e os modelos de referência do sistema.

Segundo Dempsey (1999), como o projeto é amplo, muitas empresas perdem de vista as motivações originais e naufragam diante das dificuldades encontradas. Muitos sistemas têm uma interface ruim com o usuário. Para solucionar esse problema, elas adotam outro sistema com a interface gráfica mais atraente, que facilite o uso pelo usuário. 
De acordo com Miltello (1999), nem tudo é fácil no mundo do ERP. A implantação é cara e demorada, sendo preciso submeter todos os processos a uma verificação geral. Na prática, a corporação necessita repensar toda sua estrutura, o que a leva a buscar ajuda de profissionais especializados, elevando o investimento. Taurion (1999) afirma que o redesenho de processos e as mudanças organizacionais são essenciais para alcançar os objetivos. A empresa deve abandonar a estrutura organizacional hierarquizada e se basear em estruturas ancoradas em processos. A implantação não pode ser encarada como mudança de tecnologia e, sim, como um processo de mudança organizacional. Após a implantação, ainda são necessários ajustes no sistema para solucionar os problemas de desempenho e falhas ocasionadas pela pouca familiaridade dos usuários. A interface do ERP com outros sistemas não é fácil. Pesquisa realizada por Wood Jr. (1999) revela que a decisão sobre a adoção de ERP tem sido tomada de forma apressada, alimentada pelo marketing dos fornecedores. Muitas empresas não perceberam a amplitude e a profundidade das questões envolvidas. É preciso avaliar a estratégia e a visão de futuro da empresa e identificar as necessidades de informação. Quando questionadas sobre as desvantagens, foram obtidas as seguintes respostas: não atendimento das necessidades específicas dos negócios, perda de algumas funções essenciais dos negócios, visão superficial dos processos, dependência de um único fornecedor, excesso de controles, falta de envolvimento da alta administração, planejamento inadequado, perda de histórico durante a conversão, baixa adequação entre o sistema e o contexto empresarial do País e falta de suporte adequado. A Tabela 4 disponibiliza as barreiras e dificuldades mencionadas pelos autores estudados.

Tabela 4 - Barreiras e dificuldades com a implantação de ERP.

\begin{tabular}{lcccc}
\hline Características & Autores & 1 & 3
\end{tabular}

Legenda:

1 - Dempsey (1999)

5 - Stamford (2000)

2 - Lima et al. (2000)

6 - Taurion (1999)

3 - Miltello (1999)

7 - Wood Jr. (1999)

4 - Souza \& Zwicker (2000) 
A adoção de ERP consiste em um projeto de mudança organizacional e não de informática. Há grande despreparo e desconhecimento das empresas em relação à profundidade das mudanças que estão "por trás" da implantação do sistema. Para obter resultados significativos é necessário rever a forma de operação atual e propor modificações visando à potencialidade da tecnologia que será instalada, sempre em consonância com a visão estratégica.

Quanto à equipe responsável pela implantação, deve ser experiente e ter bons conhecimentos sobre negócios. A contratação de profissionais com esse perfil é um aspecto crítico, principalmente para empresas de médio porte, pois o custo é extremamente alto, principalmente por se tratar de um projeto longo e complexo.

A análise dos processos é uma atividade fundamental na adoção de um ERP e nem sempre é realizada. É uma etapa demorada que necessita de profissionais com conhecimento do negócio e dos objetivos da empresa. O resultado da análise pode ser a modificação do processo ou a adequação da empresa ao sistema. Em muitas implantações os processos são completamente modificados e a empresa pode ter dificuldade em se adaptar às mudanças do novo sistema e dos novos processos.

Taurion (1999) destaca que a interface do ERP com outros sistemas não é fácil, pois, em geral, eles apresentam interfaces proprietárias e adaptá-las ou adaptar os sistemas existentes a essas interfaces requer esforço de desenvolvimento e programação de testes que pode se tornar algo muito oneroso para a empresa.

Outra dificuldade refere-se ao planejamento de um projeto dessa natureza. A adoção de um ERP consiste num projeto longo e caro, sendo necessária cautela na previsão do tempo de implantação e dos custos envolvidos.

Embora seja uma informação relevante, os autores discutiram valores numéricos relacionados à adoção do ERP, principalmente devido ao grande número de variáveis envolvidas para chegar ao preço final. Essas variáveis são: custo do sistema que varia de um fabricante para outro, quantidade de módulos a serem implantados, número de licenças a serem adquiridas, quantidade de horas trabalhadas pelas empresas de consultoria e ou fornecedora do sistema, modificações a serem realizadas no sistema de acordo com as necessidades da empresa, investimento em hardware necessário para o sistema e política de treinamento adotada pela empresa.

\section{A prática empresarial com ERP}

O resultado do trabalho de campo contribuiu para avaliar a orientação e o conhecimento das pequenas empresas sobre ERP. Sabe-se que empresas desse porte têm recursos escassos e muitas vezes não podem arcar com o trabalho de uma empresa especializada que oriente a aquisição desses sistemas.

\subsection{Descrição do trabalho de campo}

O trabalho de campo consistiu em uma pesquisa exploratória e empírica. Exploratória porque avança sobre um terreno pouco conhecido, procurando mapeá-lo, e empírica porque foi realizada por meio de estudo de casos reais.

Para a coleta das informações foram entrevistadas, com o auxílio de um roteiro nas empresas selecionadas, pessoas ligadas à área de informática. Ao estabelecer o contato com as empresas a serem entrevistadas e relatar o objetivo da pesquisa, os dirigentes designavam a área de informática para disponibilizar as informações desejadas em virtude de essa área ter sido responsável por todo o processo de adoção do sistema e suporte ao usuário, tendo conhecimento para disponibilizar as informações relacionadas às dificuldades enfrentadas pela empresa.

A seleção das empresas obedeceu aos seguintes critérios: empresas que haviam implantado sistemas ERPs; empresas pertencentes a diferentes ramos de atividades; acesso e disponibilidade; estar situada na Grande São Paulo; e ser classificada como pequena empresa, de acordo com o faturamento.

Para classificar as empresas, muitos são os critérios encontrados na literatura. Há critérios 
quali e quantitativos: os primeiros podem ser ilustrados pelo critério do comportamento e pela atitude da alta direção, e os segundos, pelo critério do número de funcionários ou pelo faturamento. Para os autores deste artigo, essas classificações não pareceram adequadas ao objeto em questão: os ERPs. O melhor foi observar a classificação utilizada pelas empresas que desenvolvem e comercializam esses sistemas.

Uma publicação da revista Computerworld (1999) procurava sistematizar as estratégias adotadas pelas empresas fornecedoras de soluções ERPs e os mercados-alvo. Os autores deste artigo verificavam que se tratava de critérios razoáveis para o setor por meio de entrevistas com algumas dessas empresas fornecedoras.

Assim, este artigo adotou um critério de classificação de empresas segundo o utilizado pelas empresas fornecedoras de sistemas ERPs, apresentado pela Tabela 5. Montou-se uma amostra com dez empresas que permitiu analisar diferentes setores industriais, como pode ser observado na Tabela 6 . O faturamento anual das empresas analisadas estava entre $\mathrm{R} \$ 8$ milhões e 40 milhões de reais, podendo ser consideradas pequenas empresas.

\subsection{A concepção empresarial sobre o ERP}

O segmento das pequenas empresas caracteriza o ERP com a seguinte perspectiva:

- Possui um banco de dados único.

- Permite integração entre os setores da empresa.

- Permite o acesso fácil e imediato às informações.

- Agiliza o fluxo de informações entre as diversas áreas.

- Possibilita melhor gerenciamento das informações.

Tabela 5 - Classificação voltada para o segmento das médias empresas.

\begin{tabular}{|c|c|}
\hline Classificação & Faturamento anual $(\mathbf{R} \$)$ \\
\hline Pequena & De 5 a 30 milhões \\
\hline Média & De 30 a 100 milhões \\
\hline Grande & Acima de 100 milhões \\
\hline
\end{tabular}

Tabela 6 - Ramo de atividades das empresas estudadas.

\begin{tabular}{lcc}
\hline \multicolumn{1}{c}{ Setor industrial } & Ramo de atividade & Número de empresas \\
\hline Indústria & Químico & 1 \\
& Plástico & 3 \\
& Eletrônico & 1 \\
& Metalurgia & 2 \\
Serviço & Transporte & 1 \\
& Consórcio & 1 \\
& Locação & 1 \\
Total & & $\mathbf{1 0}$ \\
\hline
\end{tabular}


- Permite a racionalização e a agilidade de processos.

- Automatiza várias tarefas administrativas, garantindo maior controle.

- Oferece suporte à tomada de decisão.

- Possibilita a atualização do parque tecnológico da empresa.

Ao confrontar o referencial teórico com a prática empresarial percebe-se que ambos têm a mesma concepção. Se forem analisados os aspectos citados na Tabela 1, os entrevistados não mencionaram que os ERPs possuem modelos de referência, consistem em sistemas genéricos, oferecem suporte ao planejamento estratégico e são considerados, na literatura, ferramentas de mudança organizacional.

\subsection{Aspectos relevantes na implantação de ERP}

A implantação de ERP nas pequenas empresas é um fato que gera preocupação e cuidados, pois esse segmento, em geral, não possui muitos recursos disponíveis para investimento em tecnologia. O trabalho de campo revelou que a pequena empresa opta por soluções cuja implantação possa ser conduzida internamente, com pequeno auxílio de empresa de consultoria, por intermédio da contratação de uma equipe pequena constituída por um gerente de projeto e um analista. A Tabela 7 ilustra a contratação de consultoria na pesquisa realizada.

$\mathrm{O}$ artigo em questão não focou o processo de migração de sistemas antigos para o ERP. Em algumas empresas visitadas sequer havia outro sistema de informação, sendo o ERP o primeiro sistema por elas adquirido.

Nesse segmento é preciso ter confiabilidade no fornecedor, pois muitos são pequenos e novos, com produtos a preços atraentes para o segmento. Porém, esses fornecedores podem ter vida curta e a empresa que adquiriu o produto corre o risco de "ficar na mão" e/ou de adquirir um produto que dificilmente acompanhará as inovações tecnológicas.

De modo geral, as pequenas empresas não realizam análise de retorno sobre o investimento. Quando feito algum tipo de estudo, é superficial, considerando os benefícios com a atualização do parque tecnológico e da possível redução do quadro de funcionários. Algumas alegaram não ter tempo suficiente para conduzir um estudo mais aprofundado, e que a contratação de uma consultoria é inviável. Os recursos disponíveis não são suficientes para uma análise de retorno e para a aquisição e a implantação da tecnologia. Embora os investimentos sejam altos, as empresas tomam as decisões de forma apressada, impulsionadas por uma onda, sem a realização de estudo mais criterioso.

$\mathrm{Na}$ seleção dos sistemas foram poucas as empresas que mencionaram realizar a adequação de funcionalidades. Neste segmento, o primeiro critério de seleção é o preço. Depois, é conduzida breve verificação das funcionalidades do sistema. Entre as dez entrevistadas somente uma realizou estudo de aderência em vários sistemas, envolvendo pessoas da área técnica e de negócio. Essa empresa já passou por uma experiência malsucedida na implantação de um sistema de informação.

Tabela 7 - Participação de pessoal próprio e consultoria na implantação do ERP.

\begin{tabular}{lccc}
\hline Externo & $\begin{array}{c}\text { Com } \\
\text { consultoria } \\
\text { externa }\end{array}$ & $\begin{array}{c}\text { Sem } \\
\text { consultoria } \\
\text { externa }\end{array}$ & Total \\
\hline Envolvimento de funcionários & $56 \%$ & $11 \%$ & $67 \%$ \\
Não envolvimento de funcionários & $33 \%$ & - & $33 \%$ \\
Total & $89 \%$ & $11 \%$ & $100 \%$ \\
\hline
\end{tabular}


Ao confrontar os pontos citados pelos autores na implantação de ERP, observa-se que a perspectiva da pequena empresa é um pouco distinta. Elas reconhecem a implantação como uma etapa crítica e estão extremamente preocupadas com o aspecto financeiro. Não mencionaram, ou desconhecem, a profundidade das mudanças pelas quais a empresa passará e não citam a importância do envolvimento e participação da alta gerência e dos usuários na implantação do sistema, da análise dos processos e da gerência do projeto. O trabalho de campo revelou que o processo de seleção foi conduzido por pessoas ligadas à área de informática.

\subsection{Resultados obtidos com a implantação do ERP}

O trabalho de campo revelou que a pequena empresa cita um amplo espectro de melhorias obtidas com a adoção de ERP. Essas melhorias podem ser agrupadas em:

1. Evolução da base tecnológica que permite:

- redução no tempo de processamento das informações;

- obtenção das informações em tempo real;

- agilidade nas tarefas da empresa, pela otimização e uniformização dos procedimentos internos.

2. Integração entre as diversas áreas da empresa:

- auxiliada pela adoção de um único sistema em toda a empresa;

- auxilia o controle e integridade das informações, pois elimina redundância dos dados;

- permite a redução do fluxo de papéis.

3. Impacto no controle e gestão da empresa que pode ser percebido por:

- diminuição no retrabalho de tarefas administrativas;

- melhoria no desempenho da empresa;
- crescimento da empresa, possibilitado pelo controle em suas tarefas;

- centralização das atividades administrativas;

- otimização da comunicação;

- tomada de decisões com informações obtidas em tempo real;

- maior comprometimento e responsabilidade do funcionário no apontamento.

4. Impacto na administração de recursos humanos da empresa, percebido por:

- redução de custos por meio da redução de mão-de-obra e de horas extras;

- racionalização de recursos;

- melhoria do nível técnico dos funcionários em informática.

Observa-se que a maioria dos resultados apontados pelos autores é percebida pelas pequenas empresas. Em relação à evolução da base tecnológica, muitas empresas estavam desatualizadas e a opção pelo ERP elevou o patamar tecnológico da empresa.

O sistema facilitou a integração entre as várias áreas da empresa. Os usuários operam a mesma base de dados e utilizam a mesma informação. Após a implantação, aumentou o controle sobre as informações da empresa e melhorou a administração do negócio, pois há mais confiabilidade nas informações armazenadas. A adoção do sistema refletiu-se nos recursos humanos da empresa. O uso do sistema melhorou a capacitação técnica dos funcionários, pois sua operação exige treinamento. Após a implantação, a empresa tornou-se mais exigente na contratação de mão-de-obra.

Alguns resultados encontrados na literatura não foram citados pelos entrevistados, os quais se referem à documentação dos processos realizados pela empresa, regras de negócio definidas pelo sistema, empresa orientada a processos, criação de base tecnológica para instalação de novos sistemas e redução dos custos na área de informática. 


\subsection{Barreiras e dificuldades}

Confrontando o referencial teórico com a prática empresarial percebeu-se que a dificuldade mais citada pelas pequenas empresas, que é a resistência dos funcionários, passa praticamente despercebida pelos autores analisados.

1. Planejamento do projeto inadequado:

- insegurança dos funcionários em relação ao manuseio e à utilização do sistema;

- participação do fornecedor na seleção do hardware mais adequado para o sistema;

- alto custo para customizar e desenvolver relatórios;

- perda de foco resultando em estouro no custo e no prazo de implantação.

2. Contratação de equipe experiente:

- dificuldade no atendimento pelo fornecedor: tempo de resposta do fornecedor é lento, o suporte técnico não é adequado, o consultor é despreparado;

- a consultoria externa é cara e o projeto tem de ser bem acompanhado, envolvendo pessoas com conhecimento técnico e de negócio.

3. Resistência dos funcionários:

- adaptação às mudanças na rotina do trabalho, decorrente da introdução do sistema;

- resistência da alta administração e dos funcionários mais antigos por não terem conhecimentos básicos em informática;

- funcionários sem qualificação técnica para dar suporte e utilizar o sistema;

- falta de confiabilidade nas informações extraídas do sistema.

É grande a dificuldade das empresas em encarar a implantação de um ERP como um projeto de mudança organizacional; nenhuma das entrevistadas mencionou ter essa visão. A seleção e a implantação foram realizadas pela área de sistemas e encaradas como um projeto de informática. Contratar uma equipe experiente é uma dificuldade citada tanto pelos autores quanto pelas empresas entrevistadas. Ambos alertam para a lentidão no suporte técnico, profissionais com baixa qualificação e custo muito alto.

A dificuldade para realizar a análise dos processos não foi mencionada por nenhuma empresa. Pode-se supor que as pequenas empresas não fazem a análise e a adequação de seus processos para a adoção do sistema, e se o fazem, trabalham de forma superficial, não dando a devida importância a essa etapa, considerada por muitos autores como crítica do processo de adoção de ERP.

Segundo os autores, o planejamento inadequado é um dos problemas mais enfrentados. No segmento das pequenas empresas percebe-se grande cautela no que se refere ao investimento necessário para um projeto dessa natureza. Muitas empresas são bem criteriosas na contratação de mão-de-obra para implantação, procurando envolver seus funcionários, reduzindo as modificações no sistema e buscando se adequar a ele. Essa adequação traz impactos ainda maiores para os usuários que, além de terem de aprender a operar o sistema, precisam "reaprender" a realizar suas tarefas com o sistema. O custo da adequação do sistema à empresa é alto.

\section{Considerações finais}

Os resultados apresentados não são suficientes para tecer considerações conclusivas sobre a adoção de ERP pela pequena empresa, porém dão uma idéia de como é realizada. A pesquisa, como mencionado, teve por objetivo oferecer informações sobre o comportamento das pequenas empresas no processo de adoção de sistemas ERPs. Diante de algumas limitações da pesquisa, como inexistência de informações imparciais sobre o assunto, amostra reduzida e perspectiva somente dos profissionais de informática, os 
autores apenas conseguiram observar uma tendência no comportamento dessas empresas e tecer algumas considerações.

A Tabela 8 sumariza os aspectos comuns e discordantes citados pelos autores e pelas empresas. É possível observar muitos pontos discordantes ou que passam despercebidos tanto para os autores quanto para as empresas. A seguir faz-se uma rápida discussão sobre esses pontos, especialmente para aqueles considerados relevantes, a saber: mudança organizacional, orientação a processos e treinamento.

Embora os autores analisados definam o sistema ERP como um projeto de mudança organizacional, com reflexos na forma de operação da empresa, na estrutura e nos aspectos culturais, não é isso que vem acontecendo nas pequenas empresas. Essas empresas reconhecem os benefícios, principalmente os relacionados à confiabilidade das informações e adoção de um sistema único para todas as áreas. Porém, não mencionaram a realização de mudanças significativas em sua estrutura ou forma de operação.

Supõe-se que as empresas entrevistadas não estejam atentas à profundidade das mudanças que podem ser realizadas com o auxílio do ERP e que este vem sendo adotado como um sistema de informação, com algumas vantagens como o fato de ser um único sistema, com módulos que atendem a várias áreas, em que as informações são armazenadas em um banco de dados único e centralizado.

Há indicativos de que as empresas, ao deixarem de investigar os benefícios e os potenciais de melhoria do sistema, acabam automatizando uma série de processos sem se dar conta do potencial e das possibilidades de melhoria no desempenho do sistema.

Embora muitos autores mencionem a orientação a processos, na prática, isso não foi verificado. Percebe-se que as empresas têm dificuldades em se estruturar em torno de seus processos, abandonando as estruturas funcionais. No caso das entrevistadas, sequer foi mencionada a orientação aos processos. Essa característica do ERP é reconhecida, porém os entrevistados implementam os processos sugeridos pelo sistema e em nada alteram sua estrutura organizacional; nenhuma mudança mais profunda é realizada. As mudanças que acontecem estão relacionadas à forma de execução das operações.

Quando confrontada a realidade empresarial com a teoria, verifica-se que, embora na teoria o sistema deva se adequar à empresa e não o contrário, na prática a situação não é bem essa. A adequação do sistema às particularidades da empresa tem custo em geral alto, porque envolve a contratação de muitas horas de consultores especializados para as modificações necessárias. As empresas não têm recursos suficientes para arcar com esse custo e se adaptam ao sistema.

Uma dificuldade citada em várias entrevistas e praticamente não mencionada na literatura consultada é a resistência dos funcionários. Isso pode estar associado: à falta de treinamento operacional, conceitual e de reciclagem, à baixa qualificação da mão-de-obra desse segmento empresarial e à resistência dos funcionários mais antigos.

Embora pouco mencionado nas fontes consultadas, as empresas devem estar atentas ao treinamento dos usuários, pois eles serão responsáveis pela entrada das informações, sendo fundamentais para o sucesso e boa utilização do sistema. O usuário do sistema precisa estar consciente da importância de manter os dados corretos e atualizados e das conseqüências de seu erro. Nas empresas entrevistadas, não foi percebida preocupação muito grande com isso. Em geral, o treinamento é oferecido para um ou dois funcionários e estes serão responsáveis pelo suporte interno e treinamento dos demais.

Comparando o investimento realizado com as melhorias alcançadas, pode-se dizer que ainda há muito ganho a ser obtido com a adoção do ERP. Os benefícios poderiam ser maiores se fosse realizada uma análise prévia dos processos e da forma de funcionamento atual da empresa. 
Tabela 8 - Autores x empresas: aspectos comuns e discordantes.

\begin{tabular}{|c|c|c|c|}
\hline & \multirow{2}{*}{\begin{tabular}{|l} 
Aspectos comuns \\
Autores e empresas
\end{tabular}} & \multicolumn{2}{|c|}{ Aspectos discordantes } \\
\hline & & Segundo os autores & Segundo as empresas \\
\hline \multirow{8}{*}{ שֶ: } & 1) Base de dados única & 1) Evolução do MRP II & 1) Atualiza base tecnológica \\
\hline & $\begin{array}{l}\text { 2) Suporta todas as áreas da } \\
\text { empresa }\end{array}$ & $\begin{array}{l}\text { 2) Possui modelos de referência } \\
\text { 3) Sistema genérico }\end{array}$ & $\begin{array}{l}\text { 2) Automatiza tarefas } \\
\text { administrativas }\end{array}$ \\
\hline & $\begin{array}{l}\text { 3) Obtenção da informação em } \\
\text { tempo real }\end{array}$ & $\begin{array}{l}\text { 4) Suporta o planejamento } \\
\text { estratégico }\end{array}$ & \\
\hline & $\begin{array}{l}\text { 4) Permite a integração das } \\
\text { áreas da empresa }\end{array}$ & $\begin{array}{l}\text { 5) Ferramenta de mudança } \\
\text { organizacional }\end{array}$ & \\
\hline & $\begin{array}{l}\text { 5) Possibilita maior controle } \\
\text { sobre a empresa }\end{array}$ & & \\
\hline & 6) Auxilia a tomada de decisão & & \\
\hline & 7) Orientação a processos & & \\
\hline & $\begin{array}{l}\text { 8) Melhor gerenciamento da } \\
\text { informação }\end{array}$ & & \\
\hline \multirow{6}{*}{ 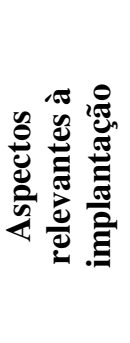 } & 1) Adequação de funciona- & 1) Análise dos processos & \multirow{6}{*}{$\begin{array}{l}\text { 1) Recursos financeiros esca } \\
\text { 2) Seleção e implantação } \\
\text { conduzidas pela área de } \\
\text { informática }\end{array}$} \\
\hline & lidades & 2) Gerência & \\
\hline & 2) Etapa crítica & 3) Mudança organizacional & \\
\hline & 3) Fornecedor confiável & $\begin{array}{l}\text { 4) Profissionais com conheci- } \\
\text { mento técnico e de negócio }\end{array}$ & \\
\hline & & 5) Treinamento & \\
\hline & & $\begin{array}{l}\text { 6) Comprometimento da alta } \\
\text { direção e dos usuários }\end{array}$ & \\
\hline \multirow{9}{*}{ 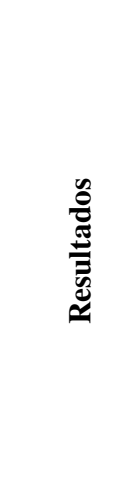 } & 1) Agilidade & 1) Processos documentados & \multirow{5}{*}{$\begin{array}{l}\text { 1) Redução no tempo de } \\
\text { processamento das } \\
\text { informações } \\
\text { 2) Adoção de um único sistema } \\
\text { 3) Centralização das atividades } \\
\text { administrativas }\end{array}$} \\
\hline & 2) Melhoria no controle e gestão & 2) Regras de negócio definidas & \\
\hline & da empresa & 3) Redução de custos na área de & \\
\hline & tempo real & \multirow{6}{*}{ 4) Empresa orientada a processo } & \\
\hline & 4) Integração & & \\
\hline & 5) Evolução tecnológica & & 4) Comprometimento dos \\
\hline & 6) Base de dados única e & & usuários \\
\hline & centralizada & & 5) Redução de custos, pela \\
\hline & 7) Melhora a eficiência & & $\begin{array}{l}\text { 6) Melhoria no nível técnico dos } \\
\text { funcionários }\end{array}$ \\
\hline \multirow{8}{*}{ 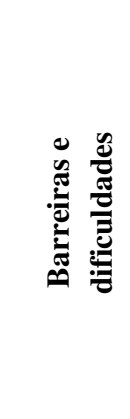 } & \multirow{2}{*}{$\begin{array}{l}\text { 1) Planejamento de implantação } \\
\text { inadequado }\end{array}$} & 1) Análise dos processos & 1) Resistência dos funcionários \\
\hline & & $\begin{array}{l}\text { 2) Atualização constante do } \\
\text { sistema }\end{array}$ & $\begin{array}{l}\text { 2) Seleção do hardware com } \\
\text { ajuda do fornecedor }\end{array}$ \\
\hline & alta administração & 3) Alguns benefícios não são & 3) Funcionários sem qualificação \\
\hline & 3) Equipe experiente & atendidos & técnica \\
\hline & 4) Dependência do fornecedor & 4) Comunicação & \\
\hline & 5) Customização cara e & 5) Interface não amigável & \\
\hline & complexa & $\begin{array}{l}\text { 6) Modelos de referência x } \\
\text { práticas específicas }\end{array}$ & \\
\hline & & 7) Mudança organizacional & \\
\hline
\end{tabular}


A "urgência" na aquisição do sistema "atropela" um passo importante, que é a verificação da real necessidade do mesmo, que é caro, complexo e implica muitas mudanças. Talvez bastasse, por ora, uma simples análise da situação atual. A implantação sem a revisão dos processos traz benefícios pequenos. Muitas vezes a solução para uma empresa de pequeno porte pode estar na revisão de seus processos, sem a necessidade de um investimento tão alto em um ERP.

A partir das reflexões realizadas são apresentadas as seguintes considerações sobre a adoção de ERPs por pequenas empresas:

- A pequena empresa reconhece os benefícios obtidos com a adoção de ERP ao analisá-lo sob a perspectiva de um sistema que possui uma base de dados única e centralizada, o que facilita a integridade dos dados. Porém, ela minimiza as potencialidades do ERP ao encará-lo como um sistema de informação, delegando toda a responsabilidade da adoção para a área de informática.

- O perfil técnico da área de informática incorre em falhas, muitas vezes cruciais ao sucesso do ERP na empresa. Por exemplo, a importância do treinamento para os usuários: sob a ótica da área de informática, o sistema é intuitivo. Para os usuários se torna imprescindível o treinamento. Sua falta ou sua realização inadequada inibe a utilização do ERP pelo usuário com menos familiaridade com a informática e pode ser o grande responsável pela resistência observada nas empresas estudadas.

- Observa-se que a aquisição do ERP nas pequenas empresas é sugerida pela área de informática para solucionar as dificuldades decorrentes de vários sistemas de informações que trabalham isoladamente. A maior dificuldade reside na falta de confiabilidade nas informações armazenadas pelo sistema.

Diante das análises realizadas, observa-se que os principais fatores que induzem as pequenas empresas a utilizarem os sistemas ERPs podem ser sintetizados em: permitir que todas as áreas trabalhem com um único sistema, integrado, de fácil manuseio e garantir a integridade e a confiabilidade nas informações armazenadas, facilitando as atividades de controle sobre as operações da empresa.

\section{Referências Bibliográficas}

BUCKHOUT, S.; FREY, E.; NEMEC JR., J. Por um ERP eficaz. HSM Management. p. 30-36, set./ out. 1999.

CENTOLA, N.; ZABEU, S. B. Pequenas e médias empresas: tomem a rédea de seus negócios! $P C$ WORLD, p. 34-54, mar. 1999.

COMPUTERWORLD. Uma tropa de elite para tocar o negócio. Disponível em: http://www.uol.com.br/ computerworld/100maiores98/software/sof_12.htm> e <http://www.uol.com.br/computerworld/100 maiores98/software/sof_12.htm>. Acesso em:1999.

CORRÊA, H. L. ERPs: por que as implantações são tão caras e raramente dão certo? SIMPÓSIO DE ADMINISTRAÇÃO DA PRODUÇÃO, LOGÍSTICA E OPERAÇÕES INDUSTRIAIS, 1. Anais... São Paulo: FGV-SP, 1998. p. 288-300.
CORRÊA, H. C.; GIANESI, I.; CAON, M. Planejamento, programação e controle da produção: MRP II/ERP: conceitos, uso e implantação. São Paulo: Gianesi Corrêa \& Associados, Atlas, 1997.

CUNHA, M. A. L. Gestão integrada de processos de negócio. SIMPÓSIO DE ADMINISTRAÇÃO DA PRODUÇÃO, LOGÍSTICA E OPERAÇÕES INDUSTRIAIS. Anais... São Paulo: FGV, 1998. p. 184-194.

DAFT, R. L. Administração. Tradução: Fernando Gastaldo Morales. Rio de Janeiro: LTC. cap. 12, p. 230-247: Mudança e desenvolvimento. 1999.

DAVENPORT, T. H. Putting de enterprise into the enterprise system. Harvard Business Review. p. 1221-1231, jul./ago. 1998. 
DEMPSEY, M. Pacote de ERP não resolve tudo. Gazeta Mercantil. Acesso em: 1999.

DELOITTE CONSULTING. ERP's Second Wave: maximizing the value of ERP_Enabled Processes. Relatório de pesquisa publicado pela Deloitte Consulting. Disponível em: http://www.dc.com/ whathsnew/second.html>. Acesso em: 1998.

HEHN, H. F. Peopleware: como trabalhar o fator humano na implementação de sistemas integrados de informação (ERP). São Paulo: Editora Gente, 1999.

INFORMÁTICA EXAME. Uma tropa de elite para tocar o negócio. mai. 1997. p. 94-97.

KRUGLIANSKAS, I. Tornando a pequena e média empresa competitiva. São Paulo: IEGE, 1996.

LIMA. A. D. A. et al. Implantação de pacote de gestão empresarial em médias empresas. Artigo publicado pela KMPress. Disponível em: http://www.kmpress. com.br>, 13 fev. 2000. Acesso em: 9 jun. 2000.

LOPES, F. et al. Revolução no setor de softwares de gestão. Relatório da Gazeta Mercantil LatinoAmericana, 26/7 a 1/8 de 1999.

MENDES, J. V.; ESCRIVÃO FILHO, E. O sistema integrado de gestão é fator de competitividade para as pequenas e médias empresas? Revista Uniara, n. 8, p. 13-21, 2000.
MILTELLO, K. Quem precisa de um ERP? Info Exame, p. 140, mar. 1999.

MONTANA, P. J.; CHARNOV, B. H. Administração. Tradução: Robert Brian Taylor. São Paulo: Saraiva, cap. 18, p. 306-320: Administrando a mudança organizacional. 1999.

SOUZA, C. A.; ZWICKER, R. Ciclo de vida de sistemas ERP. Caderno de pesquisas em administração, São Paulo. v. 1, n. 11, 1ํtrim., 2000.

STAMFORD, P. P. ERPs: prepare-se para esta mudança. Artigo publicado pela KMPress. Disponível em: http://www.kmpress.com.br/00set 02.htm>, jun. 2000. Acesso em: 13 set. 2000.

TAURION, C. Oportunidades e riscos na escolha de uma solução ERP. Artigo publicado pela gestão empresarial, edição n. 1, nov/98-jan/99. Disponível em: www.uol.com.br/computerworld/computer world/280/gcapa3.htm>. Acesso em: 24 set. 1999.

WOOD JR., T. Modas e modismos gerenciais: o caso dos sistemas integrados de gestão. Série de Relatórios de Pesquisa, NPP, Núcleo de Pesquisas e Publicações. Escola de Administração de Empresas de São Paulo, FGV. Relatório n. 16/ 1999.

\title{
THE ENTERPRISE RESOURCE PLANNING (ERP) IN SMALL BUSINESSES: FACING THEORETICAL REFERENCES AND THE BUSINESS WORLD
}

\begin{abstract}
In the last years, Enterprise Resource Planning (ERP) is being largely used by enterprises. They are presented as "the solution" for the enterprise's problems. They are generic systems able to integrate all the enterprise's informations through a single data base. The literature about this subject presents a series of positive results and benefits a firm could obtain with the systems' adoption. But the difficulties the enterprises face and the deep of changes to be realized for the achievement of the benefits are not clear to the firms, specially for the small businesses which do not have many resources to invest in technology. This paper has the objective to describe the result of a research on the adoption of ERP, by small business, opposing theoretical references and the enterprise practices.
\end{abstract}

Key words: Enterprise Resource Planning, small and medium enterprises, organizational change, integration, information systems. 